\title{
Diálogos cruzados sobre pesquisa (auto)biográfica: análise compreensiva-interpretativa e política de sentido
}

Crossed dialogues on (auto)biographical research: Interpretation-comprehensive and meening policy analysis

Elizeu Clementino de Souza*

Universidade do Estado da Bahia

Resumo O texto apresenta reflexões sobre pesquisa (auto)biográfica e narrativas de formação no campo educacional, ao destacar modos como temos construído redes de pesquisas e práticas de formação, ao sistematizar questões sobre análise compreensiva-interpretativa de narrativas, tomando como referência questões teórico-metodológicas no campo da pesquisa (auto)biográfica. $\mathrm{O}$ texto organiza-se a partir de duas ideias centrais, as quais buscam dialogar sobre a configuração dos domínios da pesquisa (auto)biográfica no contexto contemporâneo brasileiro, em seguida apresenta questões sobre políticas de sentido e interpretação de narrativas no campo dos estudos (auto)biográficos. Busca-se apresentar experiência de um projeto de centrado nas narrativas escritas por professores em processo de formação sobre diversidade afetivo-sexual e homofobia no cotidiano escolar.

PALAVRAS-CHAVE: Pesquisa (auto)biográfica, Análise de narrativas, Trabalho docente, Homofobia.

\section{Abstract}

This work offers reflections on the (auto)biographical research and formation narratives in the educational field, highlighting the way we have been using them to construct research networks and formation practices by systematizing questions about the comprehensive-interpretative analysis of the narratives, taking as reference theoretical-methodological questions in the field of (auto) biographical research. The text is developed from two central ideas which on one hand aims to dialogue about the (auto)biographical research domains configuration in the Brazilian contemporary context and, on the other hand, presents questions on sense policies and narratives interpretation in the field of (auto)biographical studies. We seek to present the experience from a project centered on written narratives made by teachers on their education process about the affective-sexual diversity and homophobia in everyday school life.

KEYWORDS: (auto)biographical research, Narratives analysis, Teachers work, Homophobia. 
No espaço-tempo contemporâneo, temos vivenciados questões legais, discussões metodológicas e ampliação do campo de pesquisa sobre as (auto)biografias no domínio das Ciências Humanas e, mais especificamente, da formação de professores (SOUZA, 2011; DELORY-MOMBERGER, 2012). Chamam-me a atenção as polaridades e discussões empreendidas sobre o lugar que ocupa o biográfico na esfera entre público e privado, nas relações postas entre vidas singulares, anonimato, respeito ao biografado e o trabalho de construção das biografias, como modo de revelar e desvelar situações cotidianas de sujeitos implicados em seus espaços pessoais e profissionais.

Do ponto de vista da tradição da pesquisa acadêmica, avançamos, desde os anos 20 (COULON, 1995), com as implicações epistemológicas dos sociólogos de Chicago, até as críticas construídas sobre as biografias individuais e coletivas (BOURDIEU, 2000), vistas como férteis para apreensão de dispositivos da vida social, humana e das diferentes formas de representações que construímos sobre a vida.

O debate instalado neste momento, no Brasil, vem se vinculando muito mais a questões jurídicas do que ao enfrentamento que se coloca na sociedade contemporânea, no que se refere às dinâmicas públicas e privadas da vida e das formas de socialização de homens comuns, de artistas, de profissionais diversos e de suas implicações com a história. O que se coloca como questão central é uma censura desvelada sobre a vida, manifestada através de discussões sobre as biografias e suas interdições, com base em um estatuto jurídico e legal, implicando significativamente na castração das representações sobre a vida em suas múltiplas complexidades.

Em contextos de pesquisas e em práticas de formação, os acordos mútuos entre sujeitos em formação bem como profissionais em acompanhamento e processos de mediação biográfica dialogam sobre o lugar da oralidade e da escrita como dispositivos que possibilitam reflexões sobre a vida, a formação, as trajetórias individuais e coletivas, bem como sobre o respeito à liberdade, autonomia e democracia individual e social. Garantir o respeito às narrativas, aos percursos de vida-formação e possíveis superações de formas de controle sobre o biografo e o biografado ou entre a escrita (auto)biográfica e as disposições de formação são férteis para explicitar contextos, conjunturas sociais, marcas individuais dos homens e mulheres em suas manifestações sobre a vida.

Postas essas questões iniciais, intenciono partilhar reflexões sobre pesquisa (auto)biográfica e narrativas de formação no campo educacional, ao destacar modos como temos construído redes de pesquisas e práticas de formação, bem como sistematizar questões sobre análise compreensiva-interpretativa de narrativas, ao tomar como referências questões teórico-metodológicas no campo da pesquisa (auto)biográfica.

\section{Narrativas e pesquisa (auto)biográfica: questões iniciais}

No campo educacional brasileiro, as pesquisas (auto)biográficas tem se consolidado como perspectiva de pesquisa e como práticas de formação, tendo em vista a oportunidade que remete tanto para pesquisadores, quanto para sujeitos em processo de formação narrarem suas experiências e explicitarem, através de suas narrativas orais e/ou escritas, diferentes marcas que possibilitam construções de identidades pessoais e coletivas. 
A consolidação dessa abordagem de pesquisa vem sendo marcada por diversos estudos ${ }^{1}$ empreendidos nos diferentes programas de pós-graduação, na criação e desenvolvimento de grupos de pesquisa e associações cientificas ${ }^{2}$ sobre tal objeto no país, nas edições de diferentes congressos ${ }^{3}$ sobre a temática, publicações de livros ${ }^{4}$ e revistas que tem se dedicado ao (auto)biográfico como modos de socialização de experiências em contextos de formação e de aprendizagens sociais e profissionais. O movimento biográfico que se desenvolve e consolida nas Ciências Humanas e Sociais, mais do que invadir a vida humana, parte de princípios deontológicos e busca assegurar a vida, ao abrir espaços para socializações e partilhas de modos próprios de como os sujeitos vivem, se desenvolvem, aprendem, enfrentam conflitos, buscam alternativas para superar as adversidades da vida frente aos processos de inclusão/exclusão social.

Ao teorizar sobre o campo da pesquisa biográfica, Delory-Momberger (2012) apresenta questões pertinentes aos pressupostos epistemológicos, as dimensões metodológicas e as possibilidades de análise. As discussões construídas pela autora buscam evidenciar configurações epistemológicas da pesquisa biográfica no domínio da sociologia, ao entrecruzar relações específicas entre o indivíduo, na sua singularidade, com o biográfico e as experiências que são construídas ao longo da vida. Destaca também aspectos relacionados à construção/produção de entrevista biográfica e categorias de análise, no que se refere aos discursos, ações, motivos e gestão biográfica, contidos nos textos narrativos.

As relações estabelecidas entre o projeto epistemológico da pesquisa biográfica e a antropologia social, conforme teorizadas por Delory-Momberger (2012), inscrevem-se na constituição dos indivíduos e suas implicações socioculturais, linguísticas, históricas, econômicas e políticas, ao explicitar marcas como os indivíduos representam-se a si mesmos e aos outros numa perspectiva temporal de sua existencialidade e das experiências construídas ao longo da vida. Assim, a pesquisa (auto) biográfica nasce do indivíduo, em sua inserção social, mediante modos próprios de biografização e de seus domínios social e singular. Da mesma forma, a temporalidade biográfica configura-se como outra vertente estruturante da experiência humana e das narrativas num tempo biográfico, ao explicitar territórios da vida individual e social, através das experiências vividas e narradas pelos sujeitos, implicando-se com princípios hermenêuticos e fenomenológicos que caracterizam a vida, o humano e suas diferentes formas de expressão e manifestação.

Ao discutir sobre entrevista narrativa, como uma das possibilidade de coleta de dados na pesquisa biográfica Delory-Momberger (2012), discute aspectos relacionados à finalidade de tal procedimento, destacando o papel da subjetividade, das experiências constitutivas da individualidade e de processos de individuação, mediante o exercício dialógico da escuta de disposições da "exterioridade social e interioridade pessoal" (2012, p. 526) dos tempos e espaços das biografias individuais e coletivas. Desta forma, entrevistar vincula-se a dimensões heurísticas, pois implica colocar-se a ouvir histórias narradas, visto que

[...] A entrevista de pesquisa biográfica instaura assim um duplo empreendimento de pesquisa, um duplo espaço heurístico que age sobre cada um dos envolvidos: o espaço do entrevistado na posição de entrevistador de si mesmo; o espaço do entrevistador, cujo objeto próprio é criar as condições e compreender o trabalho do entrevistado sobre si mesmo. (DELORY-MOMBERGER, 2012, p. 527) 
As disposições construídas num processo de entrevista abrem muitas possibilidades de sentido, formação, compreensão e marcas biográficas da vida entre entrevistador e entrevistado, frente a partilha de experiências de vida e de percursos biográficos vinculados a projetos de pesquisa ou à práticas de formação. Sobre essa questão Bolívar (2012), ao tratar de princípios epistemológicos e metodológicos da pesquisa (auto)biográfica, destaca questões sobre a abordagem qualitativa de pesquisa e a vinculação do enfoque biográfico e narrativo como uma das formas de superação de estudos pós-positivistas, centrando-se na reflexividade, na reconstrução de identidade, de percursos e trajetórias, mediante partilha de experiências e narrativas dos sujeitos implicados em processo de pesquisa e formação.

No que se refere a entrevista narrativa, Souza (2011a), ao tomar princípios teórico-metodológicos propostos por Jovchelovitch e Bauer (2002), tem construído, no âmbito do Grupo de Pesquisa (Auto)biografia Formação e História Oral (GRAFHO), experiências de pesquisa centradas nas práticas de formação com as histórias de vida e com a abordagem (auto)biográfica tanto em relação às práticas de formação, a construção da identidade docente, quanto em relação às memórias e trajetórias pessoais e institucionais de professores em processo de formação, de memórias e histórias de vida de educadores baianos. Bem como é centrada a atenção atualmente, em percursos e trajetórias profissionais de professoras que trabalham em classes multisseriadas em territórios rurais. Tais experiências de pesquisa-formação com as entrevistas narrativas, tem possibilitado ao grupo, numa perspectiva de colaboração com outros grupos de pesquisa do estado da Bahia, do Rio Grande do Norte e da França, sistematizar princípios sobre as narrativas de formação e aspectos relacionados ao trabalho docente no domínio da pesquisa (auto)biográfica.

São diversas as possibilidades de análise com fontes narrativas, (auto)biografias, memoriais e com escritas em processo de formação. Cabe aqui destacar as contribuições teóricas construídas por Poirier et. al (1999), sobre possibilidades diversas de análise interpretativa e compreensiva das histórias de vida, bem como as proposições de Pineau (2000), quando discute sobre triangulação formativa e histórias de vida em contexto de pesquisa e de formação, além das contribuições de Bolívar (2012), quando teoriza sobre aspectos teórico-metodológicos da investigação narrativa e desafios postos no processo de análise das narrativas. Tenho apreendido tanto em processo de pesquisa, quanto em processo de orientação, os desafios que são colocados para diferentes pesquisadores sobre a análise, compreensão e/ou interpretação de narrativas (auto)biográficas, seja no conjunto de suas produções textuais e linguísticas, seja através da construção de unidade de análises temáticas ou de análise de conteúdo ou de discurso como uma das possibilidades metodológicas para análise de narrativas.

\section{Diálogos cruzados, análise compreensiva-interpretativa e política de sentido}

Narrativas (auto)biográficas configuram-se como corpus de pesquisa, visto que são recolhidas de forma oral e/ou escritas pois, como afirma Poirier et. al., corpus pode ser entendido como "[...] um material qualitativo constituído por um conjunto de histórias de vida, de sujeitos saídos de um universo populacional nitidamente definido e dos fins que se procura atingir [...]" (1999, p. 108). 
Desta forma, narrativas (auto)biográficas construídas e recolhidas em processo de pesquisa e/ou em práticas de investigação-formação, configuram-se como corpus de análise, por considerar a subjetividade das fontes, seu valor heurístico e a análise interpretativa-compreensiva (RICOEUR, 1996) implicada nas trajetórias de vida, bem como pela implicação e importância que tem a narrativa em contexto de pesquisas, a partir da fenomenologia das experiências. Narrativas (auto)biográficas, construídas e/ou coletadas em processo de pesquisa ou em práticas de formação, centram-se nas trajetórias, percursos e experiências dos sujeitos, são marcadas por aspectos históricos e subjetivo frente às reflexões e análises construídas por cada um sobre o ato de lembrar, narrar e escrever sobre si.

A análise compreensiva-interpretativa das narrativas busca evidenciar a relação entre o objeto e/ou as práticas de formação numa perspectiva colaborativa, seus objetivos e o processo de investigação-formação, tendo em vista apreender regularidades e irregularidades de um conjunto de narrativas orais ou escritas, partem sempre da singularidade das histórias e das experiências contidas nas narrativas individuais e coletivas dos sujeitos implicados em processos de pesquisa e formação.

Em trabalho anterior (SOUZA, 2006a), no que se refere a escrita de narrativas da trajetória de escolarização e sobre processo de formação, busquei compreender, numa perspectiva colaborativa e de auto revelação de cada ator sobre suas experiências e lembranças, mediante implicações e distanciamentos de cada um em relação à sua escrita narrativa, conhecimentos e aprendizagens individual/coletiva construídas ao longo da vida. Conforme já explicitado em trabalho anterior,

Para a análise interpretativa das fontes utilizei a ideia metafórica de uma leitura em três tempos, por considerar o tempo de lembrar, narrar e refletir sobre o vivido. Desta forma, a interpretação aconteceu desde o momento inicial da investigação-formação tanto para o pesquisador, quanto para os sujeitos envolvidos no projeto de formação, a qual se organizou a partir dos seguintes tempos: - Tempo I: Pré-análise / leitura cruzada; - Tempo II: Leitura temática - unidades de análise descritivas; - Tempo III: Leitura interpretativacompreensiva do corpus. (SOUZA, 2006a, p. 79)

Desta experiência de análise compreensiva-interpretativa, destaco que os três tempos de análise como dimensão metodológica graduam entre si relações de dialogicidade e reciprocidade, tendo em vista que mantem entre si aproximações, vizinhanças, mas também singularidade em seus tempos, momentos de análise. Configurado como tempo de análise cruzada ou pré-análise, o Tempo I centra-se na organização e leitura das narrativas, tendo em vista a construção do perfil do grupo pesquisado, para, em seguida avançar na leitura cruzada, a fim de apreender marcas singulares, regularidades e irregularidades do conjunto das histórias de vida-formação.

Diante das questões éticas sobre as pesquisas com seres humanos, cabe aqui destacar a importância de discussão do contrato de pesquisa, ao explicitar os objetivos, suas intenções, processo de coleta dos dados, bem como a possibilidade ou não de identificação dos colaboradores da pesquisa. De fato, essa questão requer bastante atenção do pesquisador e dos colaboradores, exigindo diálogos constantes e caso tenha aquiescência, por parte do colaborador, a assinatura de termo ou carta de cessão de direitos. Outra opção é em função da impossibilidade de utilização do nome do/da 
colaborador/a no relatório de pesquisa, ou para efeitos de publicação, discutir com o/a mesmo/a possibilidade de identificação na pesquisa, a fim de preservar sua identidade.

O primeiro tempo de análise revela-se como singular, tendo em vista a construção do perfil do grupo pesquisado, tanto na perspectiva individual, quanto coletiva. A escrita do perfil biográfico busca mapear dados identificadores de cada sujeito individualmente e do grupo em sua dimensão coletiva, explicitando questões culturais, socioeconômicas, biográficas (gênero, idade, relações familiares, etc), de formação e das implicações/dificuldades em relação a narrativa oral e ou escrita. A leitura cruzada ou pré-análise, em processo de pesquisa, de formação ou de investigação-formação remete ao pesquisador para uma escuta sensível e atenta, bem como para a leitura sucessiva das fontes, implicando no cruzamento individual e coletivo das histórias dos colaboradores e do mapeamento inicial de significações e unidades temáticas de análise, por considerar os eventos narrados ou descritos sobre o objeto específico de pesquisa ou de formação, sempre centrado nos percursos, trajetórias e experiências de vida dos sujeitos e das singularidades de cada história de vida.

No processo de leitura cruzada ou na pré-análise, faz-se pertinente considerar as singularidades de cada história de vida expressa nos textos narrativos e revelados pelos sujeitos. A partir do particular e do subjetivo (FERRAROTI, 1988) de cada narrativa, implicam deslocamentos temporais e espaciais das trajetórias individual e coletiva, combinando-se, articulando-se e, muitas vezes, distanciando-se num conjunto, o do corpus, enquanto totalidade das fontes, numa perspectiva que nasce do particular para o geral e vice-versa.

No que se refere ao Tempo II - Leitura temática ou unidades de análise temática/descritiva -, cabe destacar que o mesmo vincula-se às leituras cruzadas (Tempo I), tendo em vista a construção do perfil biográfico do grupo pesquisado e a possibilidade de apreensão de regularidades, irregularidades, particularidades e subjetividades de cada história individualmente e do conjunto das narrativas do grupo, mediante a organização temática e agrupamento de unidades de análise que possibilitam a compreensão-interpretação do texto narrativo, através do seu universo de significados e significantes. Cabe destacar que o objeto central da análise temática, como tempo II, consiste na construção, após a leitura cruzada, das unidades de análise temática, tendo em vista a análise compreensiva-interpretativa.

De modo que, a análise temática visibiliza a complexidade, a singularidade e a subjetividade das narrativas, exigindo um olhar e uma leitura atentos do pesquisador, uma vez que as regularidades, as irregularidades e as particularidades apresentamse na oralidade e na escrita, através dos sentidos e significados expressos e/ou não, no universo particular das experiências de cada sujeito. A leitura analítica e a interpretação temática têm o objetivo de reconstituir o conjunto das narrativas, no que se refere à representação e agrupamento, através das unidades temáticas de análise, a fim de apreender sutilezas, o indizível, as subjetividades, as diferenças e as regularidades históricas que comportam e contem as fontes (auto)biográficas.

As contribuições e diálogos com Poirier (1999), possibilita-me compreender que a revelação das unidades de análise temática (UAT) ou unidades descritivas (UD) considera a pertinência, a homogeneidade e a heterogeneidade do conjunto das fontes (auto)biográficas ou narrativas, visto que "[...] as histórias de vida não consti- 
tuem, de modo algum, um inquérito verificatório, não visam nem estabelecer leis, nem provar hipótese; têm por função recolher testemunhos, elucidá-los e descrever acontecimentos vividos [...]" (Poirier et. al, 1999, p. 117).

Aqui, cabe explicitar algumas possibilidades de análise, após a identificação, mapeamento e apreensão de unidades de análise temática ou de unidades descritivas, as quais podem ser utilizadas na totalidade do texto narrativo biográfico ou da demarcação de excertos das narrativas (auto)biográficas. As quais remetem sempre para a complexidade e a totalidade de cada experiência narrada, seja através da pertinência e recorrência dos episódios ou das suas irregularidades e particularidades da vida em suas diferentes formas de manifestação ou de expressão.

Ao utilizar princípios deontológicos, da hermenêutica e da fenomenologia, a análise linguística e textual das narrativas (auto)biográficas pode ser construída a partir do texto em sua totalidade, como utilizada pela História Oral, ou centrada na análise temática ou descritiva, por considerar unidades de significação e excertos que representem ou revelem regularidades ou irregularidades narradas pelos sujeitos, seja individual ou coletivamente. Ainda assim, seja qual for a opção de análise, evidenciase a necessidade de constante retorno às narrativas (auto)biográficas, tendo em vista esclarecer registros e articulações dialéticas das leituras temáticas e interpretativas no processo de escrita e compreensão de percursos, trajetórias e experiências de vida dos sujeitos, mediante o agrupamento de unidades de significações.

A construção de critérios de análise nasce articulada aos processos de leitura cruzada, leitura analítica e leitura compreensiva-interpretativa, implicando-se no modo como cada sujeito elege para narrar ou escrever sobre si, suas referências socioculturais, as regularidades e irregularidades históricas dos percursos e trajetórias de vida-formação, bem como pelo aprofundamento narrativo, frente a interioridade, exterioridade e a subjetividade de cada narrativa. Ainda assim, as leituras temática, interpretativa e compreensiva permitiram, como uma dimensão meta-reflexiva e de um exercício metodológico, agrupar as unidades temáticas de análise através das recorrências e das irregularidades presentes nas narrativas, emergindo de um diálogo intertextual e de uma análise horizontal das experiências individuais e coletivas contidas nas narrativas. Conforme explicitam Poirier et. al. (1999), a "[...] análise horizontal resulta do encadeamento, trecho a trecho, da totalidade do discurso organizado pelo sistema categorial [...]" (p. 125) e ainda continuam afirmando os autores que "[...] empregamos o termo 'análise horizontal' para indicar o trabalho sobre o conjunto do 'corpus', onde a história é considerada só como um elemento de informação [...]” (idem, p. 125 - grifos dos autores).

Diante das questões postas pelos autores, faz-se necessário explicitar duas questões, a primeira diz respeito ao exercício constante de escuta e leitura para a construção de unidades de análise temática em articulação com a totalidade da história narrada, contrapondo-se a ideia de categoria. A segunda refere-se as questões postas entre pesquisa (auto)biográfica e o trabalho com as narrativas, exigindo uma posição ética no processo da pesquisa ou das práticas de formação, em função da totalidade dos conteúdos das histórias. Mesmo que a pesquisa utilize de fragmentos, aqui entendidos como unidades de análise temática, para agrupar as experiências contempladas nas narrativas e nos excertos biográficos dos sujeitos envolvidos num projeto de pesquisa ou num processo experiencial de formação inicial ou continuada. 
Ao tomar o conceito de Ferraroti (1988), de particular e geral, no que se refere as narrativas e histórias de vida, compreende-se que a análise horizontal e as unidades de análise temática possibilitam, a partir da leitura interpretativa-compreensiva, superar o agrupamento sucessivo de repetições contidas nos textos narrativos - saturação da informação -, explicitando particularidades individuais do corpus e da seleção de lembranças e experiências significativas dos sujeitos em suas trajetórias de vida, o que remete-nos à ideia de que o agrupamento das unidades de análise temática vai se constituindo mediante ao sistema de referência de cada sujeito quando narra sua própria história.

O Tempo III - análise interpretativa-compreensiva - vincula-se ao processo de análise, desde o seu início, visto que exige leituras e releituras individuais e em seu conjunto do corpus das narrativas, recorrendo aos agrupamentos das unidades de análise temática e/ou ao conjunto das narrativas e das fontes utilizadas.

Tendo em vista a ampliação dos modos de análises e das implicações da pesquisa narrativa em processo de pesquisa ou em projeto de investigação-formação, cabe destacar o lugar que ocupa a triangulação das fontes com histórias de vida, conforme explicita Pineau (2000), ao afirmar que "[...] en méthodologie des sciences humaines, la triangulation est principalement vue comme une opération de croisement de deux sources d'information permettant de comparer leurs données [...]" (p. 174). Nesta perspectiva, a triangulação de fontes narrativas e biográficas pode permitir a apreensão de questões relacionadas as trajetórias e percursos de vida-formação dos sujeitos, aprendizagens e experienciais construídas ao longo da vida, bem como questões concernentes ao cotidiano escolar, ao trabalho docente, a sexualidade, a homossexualidade e a homofobia no espaço social e escolar.

Assim, tendo em vista as questões sistematizadas sobre os três tempos de análise - pré-análise e leitura cruzada, leitura temática e leitura interpretativa-compreensiva - buscarei descrever, de forma abreviada, uma experiência de pesquisa-formação com professores da rede estadual de Salvador. A descrição debruça-se no que se refere ao trabalho docente, ao cotidiano escolar e a homofobia no espaço da vida, da formação e da prática profissional, sem contudo analisar os textos narrativos construídos no projeto.

\section{Narrativas de formação: cotidiano escolar, homofobia e trabalho docente}

Tendo em vista explicitar experiências de um projeto específico de formação, busco sistematizar aspectos relacionados às narrativas sobre trabalho docente, cotidiano escolar e homofobia, a partir de narrativas construídas por professores e professoras. Faço referência ao Projeto Direitos Humanos e diversidade afetivo-sexual na escola: homofobia, trabalho docente e cotidiano escolar ${ }^{5}$, o qual discutiu e sistematizou questões sócio-históricas sobre a homossexualidade e suas diferentes formas de representação no cotidiano social e escolar, bem como construiu modos de enfrentamento de práticas homofóbicas. Desenvolveu-se ações que fortaleceram práticas autônomas, tendo em vista incorporar concepções e práticas sobre direitos humanos e diversidade afetivo-sexual, no trabalho docente e no cotidiano escolar, no que tange às Diretrizes Nacionais e os Parâmetros Curriculares Nacionais ( $\mathrm{PCN}$ s), adequando-os às condições locais no contexto das reformas atuais da Educação Básica. 
Políticas de formação de professores poderão contribuir para a superação de práticas normalizadoras no cotidiano escolar, especialmente, no que diz respeito a homofobia e ao preconceito presentes no contexto social e escolar. Ações pontuais vêm sendo desenvolvidas pela $\mathrm{SECAD}^{6}$ (Secretaria de Educação Continuada, Alfabetização e Diversidade), por Secretarias de Educação, ONGs e suas relações com a escola, tendo em vista a redução da vulnerabilidade escolar frente às discriminações de orientação sexual, sexismo, racismo e outros no ambiente público.

A proposta do trabalho centrou-se na discussão e planejamento de Seminário de Formação sobre direitos humanos e diversidade sexual na escola, ao buscar privilegiar suas diferentes formas de manifestações e de representações no cotidiano escolar, com ênfase na construção sociocultural da sexualidade humana. Para melhor entender as relações entre sexualidade e educação, no que concerne as representações sexuais e discursos construídos por crianças, adolescentes e jovens no espaço escolar. O projeto partiu de dimensões experienciais das lembranças/memórias de formação dos professores e suas implicações com a diversidade e suas múltiplas expressões no cotidiano social-escolar.

A proposição de escritas e de relatos narrativos (autobiográficos) com entradas sobre as experiências e memórias de formação, relacionando-as com a cultura, a diversidade e a sexualidade são férteis para a ressignificação do trabalho docente na contemporaneidade. Desta forma, três questões mobilizaram a escrita dos relatos: Como vivi na família e na infância questões relacionadas a sexualidade? Como foram tratadas questões relacionadas a sexualidade e homossexualidade no meu processo de formação? De que forma lido com questões relacionadas a sexualidade e homossexualidade no cotidiano escolar?

A fim de concretizar tais possibilidades, o trabalho de formação estruturouse a partir da escrita de narrativas de formação, tendo em vista permitir que os professores pudessem construir modos de intervenção e práticas no seu cotidiano, capazes de combater o preconceito e promover a igualdade. As análises que se propõem sobre os excertos das narrativas partem da compreensão sócio-histórica e cultural das questões da diversidade, valem-se do exame de várias representações e imagens, detendo-se nos recursos artísticos (literários e cinematográficos) para promover interpretações férteis e caminha em direção à construção de alternativas práticas de trabalho.

Neste sentido, as análises construídas coletivamente, no processo de formação, partiram do pressuposto de que a escola é uma importante peça na maquinaria social de domesticação dos corpos, ocupando-se, assim como outras instituições, da construção das masculinidades e feminilidades, heterossexualidades e homossexualidades e, portanto, também da norma e do desvio. A explicitação de tais argumentos partem da pesquisa realizada por Souza (2007), tendo em vista apreender modos como a escola, enquanto espaço educacional formal concebe a sexualidade e constrói dispositivos sobre a homossexualidade, no cotidiano escolar, e quais discursos são veiculados sobre a homofobia.

No que se refere ao modo como os sujeitos vivenciam em seu cotidiano familiar e nas práticas de formação, questões sobre a sexualidade e a homossexualidade, diversos textos narrativos partilhados no Seminário de Formação evidenciaram silenciamentos por parte da família, bem como a clareza por parte da escola de formas 
de enfrentamento dos preconceitos e das diferenças no seu cotidiano. A possibilidade de constituição de uma escola plural, humanizadora e promotora da igualdade exige o entendimento das configurações assumidas pelas desigualdades nos vários quadros sociais e institucionais e a construção de estratégias que possam promover a integração, tendo em conta as relações de gênero e a pluralidade étnico-cultural. Nesse sentido, a escola comparece como espaço privilegiado para a integração, o respeito as diferenças.

Vivemos numa sociedade marcada pela pluralidade de imagens e de diferenças socioculturais. A escola, por sua vez, busca desenvolver seu projeto pedagógico com ênfase nas diferenças e nas relações que os indivíduos estabelecem consigo próprios e com os outros. Convém questionar, se nós, professores, desenvolvemos nossas práticas, tendo em vista a assunção das identidades e o respeito às diferenças? Como podemos viver os projetos de igualdade e respeito à diversidade, tão presente e marcadas na sociedade brasileira? De que maneira a escola pode tornar-se um território favorável à aprendizagem do convívio com a diferença?

Compreendo a educação como um processo de autotransformação do sujeito que envolve e provoca aprendizagens em diferentes domínios da existência, evidencia-se o processo que acontece em cada sujeito, traduzindo-se na dinâmica que estrutura ou é estruturada por cada um no seu modo de ser, estar, sentir, refletir e agir. Sendo assim, a educação e, por consequência, a formação não se esbarram na transmissão e aquisição de saberes, na transferência de competências técnicas e profissionais e tampouco na assertiva das potencialidades individuais. Filio-me à perspectiva epistemológica da formação experiencial, por entender que a noção de processo de formação que essa perspectiva implica possibilita o centramento no sujeito e na globalidade da vida, entendida como interação da existência com as diversas esferas da con-vivência como perspectiva educativa e formativa.

Referências

ABRAHÃO, M. H. M. B.; PASSEGGI, M. C. (Orgs.). Dimensões epistemológicas e metodológicas da pesquisa (auto)biográfica. Natal: EDUFRN; Porto Alegre: EdiPUCRS; Salvador: EDUNEB. (Coleção Pesquisa (Auto)Biográfica: temas transversais. V. 1 Tomo I, 2012)

ABRAHÃO, M. H. M. B. (Org.). Pesquisa (auto)biográfica: teoria e empiria. Porto Alegre: EDIPUCRS, 2004.

BOURDIEU, P. A ilusão biográfica. In.: FERREIRA, M. M., AMADO, J. Usos \& abusos da História Oral. 3a Edição, Rio de Janeiro: Fundação Getúlio Vargas, 2000, p. 183-191.

BUENO, B. O.; CHAMLIAN, H. C.; SOUSA, C. P.; CATANI, D. B. Histórias de vida e autobiografias na formação de professores e profissão docente (Brasil, 1985-2003). Educação e Pesquisa, São Paulo, vol. 32, n. 2, p. 385-410, 2006.

COULON, A. A Escola de Chicago. São Paulo: Papirus, 1995.

DELORY-MOMBERGER, C. Abordagem metodológica na pesquisa biográfica. Revista Brasileira de Educação, v. 17, n. 51, 523-740, set./dez. 2012.

FERRAROTI, F. Sobre a autonomia do método biográfico. In: NÓVOA, A.; FINGER, M. O método (auto)biográfico e a formação. Lisboa: MS/DRHS/CFAP, 1988, p. 17-34.

JOVCHELOVITCH, S.; BAUER, M. Entrevista narrativa. In: BAUER, M. W. ; GASKELL, G. (Org.). Pesquisa qualitativa com texto, imagem e som: um manual prático. Petrópolis, Rio de Janeiro: Vozes, 2002, p. 90-113. 
PASSEGGI, M. C. (Org.). Tendências da pesquisa (auto)biográfica. São Paulo: Paulus; Natal: EDUFRN, 2008.

PASSEGGI, M. C.; SOUZA, E. C. (Dir.). (Auto) Biografia: formação, territórios e saberes. Natal: EDUFRN; São Paulo: PAULUS, 2008.

PINEAU, G. Temporalités em formation: vers de nouveaux synchroniseurs. Paris; Anthropos, 2000.

POIRIER, J. et al. Histórias de vida: teoria e prática. Trad. de João Quintela. Oeiras: Celta, 1999.

RICOEUR, P. Teoria da interpretação. Trad. de Artur Morão. Lisboa: Edições 70, 1996.

SILVA, V. L. G.; CUNHA, J. L. (Orgs.). Práticas de formação, memória e pesquisa (auto) biográfica. São Paulo: Cultura Acadêmica, 2010.

SOUZA, E. C.; BRAGANÇA, I. F. S. (Orgs.). Memória, dimensões sócio-históricas e trajetórias de formação. Natal: EDUFRN; Porto Alegre: EdiPUCRS; Salvador: EDUNEB, v.3, 2012.

SOUZA, E. C. Memória, (auto)biográfica e diversidade: questões de método e trabalho docente. Salvador: EDUFBA, 2011.

SOUZA, E. C. Territórios das escritas do eu: pensar a profissão - narrar a vida. Educação, Porto Alegre, v. 34, n. 2, p. 213-220, maio/ago. 2011a.

SOUZA, E. C. (Org.). (Auto)biographie: écrits de soi et formation au Brésil. Paris: L'Harmattan, 2008. (Coleção Histoire de Vie, Direção Gaston Pineau).

SOUZA, E. C. Fabricação de identidades e estruturação de dispositivos pedagógicos: a homossexualidade, a família e a escola. In.: SOUSA, C. P.; CATANI, D. B. Multiplicidades culturais: projetos de formação e trabalho escolar. São Paulo: Escrituras: 2007, p. 93/109.

SOUZA, E. C. S. (Org.). Autobiografias, Histórias de vida e Formação: pesquisa e ensino. Porto Alegre: EDIPUCRS; Salvador: EDUNEB, 2006.

SOUZA, E. C. O Conhecimento de si: estágio e narrativa de formação e professores. Rio de Janeiro: DP\&A; Salvador: UNEB, 2006a.

SOUZA, E. C.; SOUSA, C. P.; CATANI, D. B. La recherche (auto)biographique et l'invention de soi au Brésil. In.: PINEAU, Gaston (Dir.). Le biographique, la réflexivité et les temporalités. Paris: L'Harmattan, 2008, p. 155-170.

SOUZA, E. C.; MIGNOT, A. C. V. (Orgs.). Histórias de vida e formação de professores. Rio de Janeiro: Quartet: FAPERJ, 2008.

SOUZA, E. C.; ABRAHÃO, M. H. M. B. (Orgs.). Tempos, narrativas e ficções: a invenção de si. Porto Alegre: EDIPUCRS; Salvador: EDUNEB, 2006.

STEPHANOU, M. Introdução - Jogos da memória nas esquinas dos tempos: territórios e práticas da pesquisa (auto)biográfica na pós-graduação em Educação no Brasil. In.: SOUZA, E. C.; PASSEGGI, M. C. (Orgs.). Pesquisa (auto)biográfica: cotidiano, imaginário e memória. Natal, RN: EDUFRN; São Paulo: Paulus, 2008, p. 18-53.

VICENTINI, P. P.; ABRAHÃO, M. H. M. B. (Orgs.). Sentidos, potencialidades e usos da (auto)biografia. São Paulo: Cultura Acadêmica, 2010. (Série Artes de viver, conhecer e formar)

\section{Notas}

${ }^{1}$ Sobre os estudos relacionados ao estado da arte sobre pesquisa (auto)biográfica no campo educacional brasileiro, cabe consultar os seguinte trabalhos: Bueno, Catani, Sousa e Chamlian (2006); Souza, Sousa e Catani (2008), Stephanou (2008). 


\section{Elizeu Clementino de Souza}

${ }^{2}$ Cabe aqui destacar o pioneirismo da Associação Internacional das Histórias de Vida em Formação e da Pesquisa Biográfica em Educação (ASIHVIF-RBE), no contexto francófono e o trabalho da Associação Brasileira de Pesquisa (Auto)Biográfica (BIOgraph) e da Associação Norte e Nordeste das Histórias de Vida em Formação (ANNIHVIF) no campo educacional brasileiro.

${ }^{3}$ Do mesmo modo a rede de pesquisa propiciada pelo Congresso Internacional de Pesquisa (Auto)Biográfica (CIPA), com as diferentes edições do congresso (I CIPA, 2004, Porto Alegre; II CIPA, 2006, Salvador; III CIPA, 2008, Natal; IV CIPA 2010, São Paulo; V CIPA, 2012, Porto Alegre e a organização no VI CIPA previsto para 2014, no Rio de Janeiro), evidenciam consolidação de redes de pesquisas e de trabalhos sobre as (auto)biográficas como dispositivos de investigação, de formação e de pesquisa-formação no campo educacional no País.

${ }^{4}$ Aqui cabe destacar as publicações que resultaram das diferentes edições dos CIPA, especialmente o livro de Abrahão (2004); Souza e Abrahão (2006); Souza (2006); Souza (2008); Passeggi e Souza (2008), Souza e Mignot (2008), Vicentini e Abrahão (2010); Silva e Cunha (2010), Abrahão e Passeggi (2012), Souza e Bragança (2012), bem como as coleções: Pesquisa (auto)biográfica \& Educação (2008); Artes de Viver, Conhecer e Formar (2010) e Pesquisa (Auto)Biográfica: temas transversais (2012), as quais apresentam um conjunto de textos de pesquisadores brasileiros, latino-americanos, europeus e norte-americanos sobre questões teóricas e metodológicas da pesquisa (auto)biográfica.

${ }^{5}$ Projeto desenvolvido pela Diretoria de Formação e Experimentação Educacional - DIRFE / IAT /SEC, no período de junho 2008 a dezembro de 2008, através dos Seminários de Formação em escolas Polos de Salvador, com Consultoria de Elizeu Clementino de Souza e Osvaldo Fernandez. O referido projeto buscou discutir e sistematizar questões sócio-históricas sobre a homossexualidade, mapear representações dos(as) professores(as) sobre a temática trabalhada, tendo em vista a proposição coletiva de modos de enfrentamento de práticas homofóbicas na escola.

${ }^{6}$ Quando no início do Governo Dilma, a SECAD passou a ser denominada de SECADI (Secretaria de Educação Continuada, Alfabetização, Diversidade e Inclusão), mudando completamente sua política de ação em relação aos projetos sobre diversidade afetivo-sexual na escola.

* Professor Doutor da Universidade do Estado da Bahia, Salvador, Bahia - Brasil.

\section{Correspondência}

Elizeu Clementino de Souza - Universidade do Estado da Bahia, Departamento de Educação, Campus I. Estrada das Barreiras, s/n, Narandiba, CEP: 41150-350 - Salvador, Bahia - Brasil.

E-mail: esclementino@uol.com.br

Recebido em 14 de outubro de 2013

Aprovado em 27 de novembro de 2013 